ISSN: 2576-2141

\title{
'This Is Not What It's Supposed to Be Like': Avoiding Unwelcome Identifications Associated with Public Breastfeeding
}

\author{
Paola Taormina \\ Queen Margaret University, UK \\ Chris McVittie ${ }^{1}$ \\ Queen Margaret University, $U K$ \\ Andy McKinlay \\ The University of Edinburgh, $U K$
}

\begin{abstract}
From a discursive perspective, identities fall to be understood not as inherent properties of individuals but rather as matters that are negotiated within and emerge from social interactions with others. Adopting this perspective, we examine how mothers who breastfeed their infants in public negotiate issues of identity. The activity of public breastfeeding presents problems for identity in that it is often seen by others, and sometimes by breastfeeding mothers themselves, as socially inappropriate in that by engaging in public breastfeeding women are partly exposing their bodies. The aim of this study was to investigate how mothers who breastfeed their infants in public seek to address identity problems that can arise from engaging in this activity. We examine discussions from a focus group conducted with five members of a drop-in support group for breastfeeding mothers. Discourse analysis of group discussions shows that group members provide descriptions of difficulties that they have experienced when breastfeeding in public, and partly exposing their bodies to co-present others. These descriptions, however, rely on detail that allows the participants or other group members to undermine them and to ward off the potentially negative identities with which they are associated. The descriptions, then, are designed to attend to social concerns surrounding public breastfeeding and thereby to allow participants to construct identities that are not associated with problems.
\end{abstract}

KEYWORDS: Describing Actions, Discourse Analysis, Identities, Mothers, Public Breastfeeding.

The issue of identity and how individuals are identified by others is one that is of longstanding interest to discursive researchers. Within a discursive approach, language is treated as a topic of study in itself rather than as a resource for studying what is occurring elsewhere, either in terms of individuals' inner worlds or by way of descriptions of an external social reality. The approach emphasises the constructive property of discourse, that is that individuals in using discourse are not (merely) describing social phenomena, but rather are actively constructing versions of social actors, actions, and events. The versions that individuals construct are designed to accomplish particular outcomes in the local settings in which people

\footnotetext{
${ }^{1}$ Corresponding Author E-mail: cmcvittie@qmu.ac.uk
} 
are involved, such as accounting for and justifying their own actions, blaming or criticizing others, offering explanations, and so on. One particular focus in this approach is on identities. From a discursive perspective, identities fall to be understood not as inherent properties of individuals but rather as matters that are negotiated within and emerge from the range of interactions that we each have with others in our everyday lives (McKinlay \& McVittie, 2008; 2011; Tracy \& Robles, 2013; Wiggins, 2017). Identities therefore come to be examined as participants' concerns, with the focus being on how individuals in interaction claim, resist, and rework the identities that are available to themselves and those with whom they interact.

Central to such processes are the actions and events that might or might not be associated with specific ascriptions of identity: different versions of actions can make available very different forms of identity for those involved, making certain identities more relevant in the local context while precluding or rendering more problematic other claims (McKinlay \& McVittie, 2011). In a discussion of how people assemble accounts of actions and events, Potter (1996) noted that activities and events enter discourse by means of descriptions and that one and the same activity or event is susceptible to a whole range of potential descriptions. As Potter (1996) pointed out, 'a central feature of any description is its role in categorization; a description formulates some object or event as something ... it presents something as good or bad ... as routine or, conversely, exceptional' (p. 111). What this means is that whether an activity is categorized as being one sort of thing or another depends on how that activity is introduced into discourse through its description. And, the categorization that is applied in any particular instance, for example 'good' or 'bad', will thereby make available one form of identity or another, for example a positive identity or a negative identity, for the individual being described in relation to the activity. It is in this sense that descriptions, categorizations and identifications can be thought of as participants' concerns (Widdicombe, 1998). Individuals display a sensitivity to the sorts of categorizations and identifications that their own descriptions, and those of others, make available and they address such sensitivity in the way they produce their talk.

One example of how activities can be categorised in talk and how participants are seen to attend to the identities that specific forms of categorisation make available was provided by Potter (1996) in an analysis of talk drawn from a counselling session involving a couple, Connie and Jimmy. In that session, much of the dispute surrounding the couple's relationship, and consequent accountability for the problems encountered within it, rests on how specific activities of Connie are to be understood. Potter discusses how events on one particular night are described by Jimmy as Connie behaving inappropriately in that she pulled up her skirt to display her legs to another boy, Dave. In producing this description, Jimmy provides detail of Connie's actions which allows Connie's behaviour to be categorized in negative terms such that Connie's identity as a woman who behaves sexually inappropriately can be established.

Potter (1996) noted that descriptive accounts of this sort, which provide a range of detailed information about relevant actions or events, can be rhetorically powerful in that the description on offer comes to be heard as factual and, therefore, accurate. However, Potter also notes that such provision of detail can be 'a double-edged rhetorical weapon' (p. 168). Potter explains this as he goes on to describe Connie's response. He notes the way that Connie's response displays a sensitivity towards the potential categorization and identification Jimmy's description makes available by attending to the details Jimmy provides. Connie does this by reworking those details stating, for example that her skirt was only 'a bit shorter' and that 'I never looked at that particular bloke' (p. 167). Thus, by challenging the very details of Jimmy's description that were designed to have rhetorically established it as factual and accurate, she is thereby able to undermine the negative characterisation that Jimmy's description made available and so, in consequence, 'dodge' the identity of being a woman who behaves inappropriately. 


\section{Appropriate/Inappropriate Behaviour}

The categorization of activities in ways that raise potentially problematic issues for those involved is of course found in numerous everyday contexts beyond those of the counselling session. One such instance, in which how an activity is described influences the way the people engaged in it are identified, arises in relation to the activity of breastfeeding in public. Breastfeeding, in which a woman feeds an infant child with milk drawn from her breast, is an activity that is as ancient as the history of the human race. It is, then, perhaps surprising to discover that in contemporary society breastfeeding is associated with issues of controversy. However, a range of previous research has indicated that the activity of breastfeeding, especially the notion of breastfeeding in public, is one that is sometimes viewed in a contentious light. On the one hand, the breastfeeding mother is often regarded in a positive manner, with the action of breastfeeding being associated with positively valued identities such as that of 'the good mother' (Shaw et al., 2003). Indeed, it is only recently that the UK's statutory body for midwifery, The Royal College of Midwives, has acknowledged that the alternative to breastfeeding, bottle-feeding, is an activity to be supported, advocating in a new report (The Royal College of Midwives, 2018), for the first time, support for women who choose to formula-feed their babies instead of breastfeeding.

However, on the other hand, a woman who exposes her breast in public may be perceived to be acting in a socially inappropriate manner (Cripe, 2017). As Mahon-Daly and Andrews (2002) argue, onlookers may view public breastfeeding as an activity that breaches social norms and cultural boundaries because public exposure of breasts may be perceived as related to sexual activity. Moreover, as Johnston-Robledo and colleagues (Johnston-Robledo et al., 2007) note, even in cases where an onlooker attends to the issue of breastfeeding as involving a mother feeding an infant, they may nevertheless simultaneously be perceiving the mother's breast as a sexual object.

Other previous research has shown that breastfeeding mothers themselves display an awareness of the fact that public breastfeeding may be viewed ambiguously, either as praiseworthy or as blameworthy. For example, Acker (2009) and McFadden and Toole (2006) pointed to how some women express feelings of embarrassment associated with breastfeeding in public. Such feelings, according to Scott and Mostyn (2003), arose in particular when women give consideration to the potential responses of others with whom they share a public space. In a similar vein, Stearns (1999) argued that breastfeeding mothers themselves are especially prone to experience feelings of discomfort when breastfeeding in the presence of male observers (see also Boyer, 2018; Carathers, 2017). Such findings indicate that even among women who positively evaluate the identity of breastfeeding mother there is acknowledgement of the danger of being identified as one who acts in a socially inappropriate manner.

To date, the issue of how mothers negotiate the social aspects of breastfeeding and associated identifications has been left relatively unexamined. Instead, the focus has been on how others construct breastfeeding in ways that are designed to promote it to mothers as a desirable activity. Locke (2009), for example, shows how counsellors in ante-natal sessions draw upon versions of breastfeeding as 'natural' and breastfeeding as 'taught' in seeking to alleviate mothers' concerns and to position them as individuals who should breastfeed their infants. Other work (Burns et al., 2012; Fenwick et al., 2013) has shown how midwives' talk in interactions with mothers is designed primarily to promote breastfeeding as a beneficial activity and thereby to convince mothers that they should follow such practice. Such efforts, in both cases, paid little regard to mothers themselves or to the social settings in which they found themselves. There remains therefore a need for further understanding of how mothers, themselves, make sense of their actions and their identities. 


\section{The Present Paper}

In this paper, we take up the issue of how mothers who breastfeed in public seek to avoid the potentially problematic identification associated with this activity. And, in doing so, we examine specifically how detailed descriptions of activities can be put to use in attending to unwelcome identifications.

As noted above, in his analysis of issues of description, categorization and identification in a specific counselling session, Potter pointed out that Jimmy provided detailed descriptions of his partner's inappropriate behaviour in seeking to establish a particular identification of Connie. But it was those very details that allowed Connie to rework the issues at hand and thereby to undermine the identification of her that Jimmy had produced. In the present case, we consider the reverse case, one in which the individual at risk of being identified in a negative manner herself provides detailed descriptions of activities on which such an identification might be ascribed. As we see below, however, these details again function in a double-edged way, not only making available a negative identity but also offering possibilities for undermining such an identification. The aim of the present study was to examine how mothers who breastfeed in public ward off negative identifications that might be associated with this activity.

The first author is a young mother who had experienced some hesitation in public breastfeeding herself when her child was an infant. This stimulated her to try to understand the ways in which mothers make sense of their own activities in breastfeeding. In particular, she wished to explore the extent to which women have resources available to them to challenge or disrupt common research findings that public breastfeeding is problematic.

\section{Method}

\section{Data}

The data for the present study were collected from a focus group discussion conducted with breastfeeding mothers who attended a breastfeeding drop-in support group in a small town on the outskirts of Edinburgh, UK. This support group meets on a weekly basis and provides support both to new mothers and to breastfeeding mothers with older infants. Following an initial approach via the group organizer, five members of the group agreed to participate in the study. The participants ranged in age from 32 to 40 years, with babies ranging in age from 6 to 10 months, and all attended the breastfeeding group on a regular basis.

The focus group discussion was held on the premises of the drop-in support group. The discussion lasted approximately ninety minutes. The discussion was guided by a limited number of open-ended questions that invited participants to discuss what breastfeeding meant to them, their experiences of breastfeeding with family and friends, and their experiences of breastfeeding in public places. Probes and back-channelling ('uh huh', 'right', etc.) were used to encourage participants to develop and expand on their responses as appropriate. The discussion was audio-recorded and subsequently transcribed, using an abbreviated form of the conversation analytic notation system developed by Jefferson $(2004)^{2}$. Pseudonyms were substituted for participants' and children's names to preserve anonymity and confidentiality.

Focus group discussions, as previous researchers have noted, differ from everyday

\footnotetext{
2 Transcription symbols used here are as follows:

$(($ cough $))-$ Transcriber descriptions of sounds appear in double parentheses.

(.) - A dot within parentheses indicates a brief pause between utterances.

(2.5) - Numbers between parentheses indicate a pause between utterances measured in seconds.

e::h - Colons indicate that the immediately preceding sound has been prolonged.

$>$ text $<-$ Left and right carats indicate faster speech.

${ }^{\circ} \mathrm{I}$ know $^{\circ}-$ Degree signs indicate speech that is hearably quieter.
} 
naturally-occurring interactions. Instead of comprising everyday talk, such discussions reflect the 'interactional choreography' (Puchta \& Potter, 2004) of research settings. These settings are of course researcher-led, and reflect, at least in part, researchers' rather than participants' concerns. Consequently, the stakes for participants can be lower than would be found elsewhere (Stokoe, 2010). A number of writers (e.g. Edwards, 2003; Stokoe, 2010; Stokoe \& Edwards, 2007), therefore, have argued that researchers should rely on analysis of naturally-occurring talk instead of that found in these settings. Such concerns, however, can be addressed in contexts where group members are previously known to each other and are familiar with interacting in such a group setting: focus groups that draw upon 'pre-existing or naturally occurring social groups such as ... people who have experienced the same problem' can generate data that are especially rich and valuable in research terms (Wilkinson, 1999, p. 226). Moreover, as other writers (Gammie et al., 2017; Hennink, 2014) have noted, a single focus group discussion can generate a range of issues comparable to that produced in a series of indepth interviews with the same number of participants. The group interaction in such cases allows for detailed discussion and exploration of the concerns that are most relevant to the participants in their own terms.

For such reasons we recruited, for participation in the focus group, mothers who regularly met with each other in the support group setting to discuss matters relating to breastfeeding. Using this format, rather than examining discussions of the support group itself, allowed other users of the support group who did not wish to participate in the study to continue to engage fully in the services on offer. The group facilitator, identified in the extracts below as Jo, was herself a breastfeeding mother with a young infant. This design provided for the conduct of a group discussion that so far as possible resembled a naturally-occurring encounter within the support group, with participants drawing on their familiarity with interacting with coparticipants and bringing their own concerns to the discussions.

\section{Analysis}

A first-pass coding of the transcript was conducted to identify all passages in which participants were seen to produce descriptions of their experiences of breastfeeding in public. This initial stage was inclusive in that all passages that might be potentially relevant were included before moving on to further analysis and produced an extensive number of passages for further consideration. Extracts were then subjected to a more detailed analysis, drawing on principles of conversation analysis (Sacks, 1992), ethnomethodology (Garfinkel, 1967), and discursive psychology (Edwards \& Potter, 1992), in order to examine how each participant's description was designed, and how other group members oriented to that description in producing a response. This analysis also examined specific features of these descriptions including the way in which the details that were provided made available specific identifications of the speaker and how these details were thereafter taken up or reformulated by others copresent. The study was conducted in accordance with the principles set out in the British Psychological Society's Code of Human Research Ethics (British Psychological Society [BPS], 2014) and ethical approval was granted by a university ethics committee.

\section{Results}

Above, we noted that previous research suggested that breastfeeding in public can be viewed as socially inappropriate behaviour and indicated that breastfeeding mothers themselves display a sensitivity to this issue. One point that has received little attention in previous research is that mothers who engage in public breastfeeding can themselves describe their activities in just such a manner. We begin by examining one passage in the current data in which the participant produces such a description and the consequences of so doing for the identities of 
mothers who engage in this action. In the subsequent extracts, we examine how participants produce descriptions that are designed to attend to the possibility of problematic identity.

\section{Unwelcome Identity in Description Without Detail}

The first extract comes from a point in the group discussion where participants have been discussing whether more should be done to promote public breastfeeding. We see one participant, Jan, introduce one description of public breastfeeding that she associates with a highly negative evaluation of the activity.

\section{Extract 1 \\ 1 Jan I've never yet met a mom who's been (.) cool >about the idea< \\ 2 before she's done it (.) well would you? Would anybody? Why \\ 3 would anybody feel cool about the idea of getting their tits out in \\ 4 public? It's a weird idea.}

Here we see Jan reformulate breastfeeding in public as a specific behaviour on the part of the mother, that is that she must expose her breasts in public. This activity is, moreover, portrayed in very negative terms, through the use of the idiomatic 'getting their tits out'. Not only does this reformulation emphasise the partial exposure of the body, but it also places that exposure in a potentially sexualised context through the description that is selected. There is no reference to any alternative version of these actions, such as comprising the activity of nurturing an infant. The description thus works to construct public breastfeeding as a problematic and potentially socially inappropriate activity.

The identification that Jan's description makes available for mothers who engage in public breastfeeding is, then, a highly problematic one. In the remainder of her turn, she sets out how this potential ascription of identity leads to mothers having a negative emotional response to the activity that she has described, stating that they have not 'been (.) cool'. She warrants her knowledge of this response, by reference both to her own experience and to discussions that she has had with others, emphasized through the extreme case formulation 'I've never yet met a mom who's been (.) cool'. As Pomerantz (1986) points out, formulations of this sort are produced not with the expectation that they will be taken as literally true, but rather that they will be taken as indicators of the speaker's commitment to the claim being advanced. Further emphasis is given to Jan's claim through the subsequent listing of questions which are designed to indicate the level of agreement amongst others. Although the first question is addressed to other group members, the subsequent questions, in referring to 'anybody', emphasize the wide extent of such feelings. It is this all-encompassing negative reaction that she encapsulates in her upshot that the activity she describes is 'a weird idea'.

One further point that we can note from Extract 1 is the form in which Jan presents her reformulation of public breastfeeding. While her reference to 'getting their tits out' is certainly graphic, it does not include any detail beyond that of what is presented as problematic. Instead, the use of idiom treats the description as self-evident and standing in need of no further warrant (Drew \& Holt, 1989). And, in doing so, it makes the description on offer, problematic as it is, relatively robust to undermining and presents mothers who breastfeed in public facing considerable discursive work if they are to dodge the unwelcome identity that is in play.

\section{Avoiding Unwelcome Identity Through Detailed Description}

The group members at many points of the discussions described their experiences of the difficulties they encountered while breastfeeding in public. Although on one level, these descriptions often appeared to reflect concerns similar to those expressed by Jan in Extract 1, 
referring to issues involved in partially exposing their bodies, the participants' descriptions were presented in a form that was markedly different from that seen above.

Extract 2 follows on from a discussion among group members of the use of 'baby aprons' to provide cover whilst breastfeeding. These are items that cover up breastfeeding mothers and their infants and allow women to breastfeed in public whilst hiding from public view the baby sucking at the breast.

\begin{tabular}{|c|c|c|}
\hline \multicolumn{3}{|c|}{ Extract 2} \\
\hline 1 & Jo & What e:h what certain places would you use that? \\
\hline 2 & Val & I remember going out (.) for the first time to a restaurant for \\
\hline 3 & & lunch (.) and there was only us and an elderly couple in there (.) \\
\hline 4 & & so I used it then. \\
\hline $\begin{array}{l}5 \\
6\end{array}$ & Jo & $\begin{array}{l}\text { Why do you think that you needed to use that in that specific } \\
\text { place }\end{array}$ \\
\hline 7 & Val & They were (.) they were $>$ there $<$ and we were $>$ here $<$ and it was \\
\hline 8 & & just them and us (.) I felt that I wanted to do it for myself and I \\
\hline 9 & & also felt that it would have been more comfortable for them (.) \\
\hline 10 & & that I kept covered up and (.) it wasn't the fact that I was \\
\hline 11 & & breastfeeding in public it was more that because (.) ah (.) when \\
\hline 12 & & she was really little it was hard to latch on so there was a lot of \\
\hline 13 & & kind of preparation (.) I mean with my boob out and on and off \\
\hline 14 & & as well and I I guess it was just more that the the people (.) \\
\hline 15 & & being able to maintain my own dignity. \\
\hline
\end{tabular}

In response to an initial question from the group facilitator, Val describes a specific occasion when she used a baby apron while breastfeeding in public. In the course of providing her description, she refers at line 13 to her actions on this occasion as involving having her 'boob out', a reference that echoes Jan's reference in Extract 1 to mothers 'getting their tits out in public'. Although potentially then, this statement if unqualified might give rise to the same issues of identity seen in Extract 1, here Val attends to such possibilities through a rather more detailed description of the activity than was seen in Jan's matter-of-fact formulation earlier.

Here, Val sets out her action of having her 'boob out' in a context involving her own actions, those of her baby, and those of others present. And, she provides details of each element of this context in seeking to disavow an identity that might be associated with the activity of exposing part of her body in public. First, she refers to her own choice of using a baby apron at line 8 as being something 'that I wanted to do', suggesting that she took steps to avoid the exposure that might be viewed as problematic. The use of a baby apron, she argues allowed her to remain 'covered up' (line 10). Second, she refers to the actions of her baby and their consequences for breastfeeding in public, arguing at lines 11 to 13 that "when she was really little it was hard to latch on so there was a lot of kind of preparation'. This again serves to suggest that any potential exposure was not due to a choice on her part but instead to the difficulties involved in breastfeeding a young infant. Finally, Val describes those co-present at this time as being few in number, namely 'only us and an elderly couple' (line 3), a description that might be taken to signal that her actions would be noticeable to a greater extent than would otherwise be the case. She attends to the possibility that her actions of having her 'boob out' would be particularly obvious to those others in this instance, referring to her use of the baby apron to ensure that her breastfeeding 'would have been more comfortable for them' (line 9).

This detailed description thus is designed to ward off the possibility that Val's actions should be understood as exposing part of her body in public. It leads to her upshot at line 15 that, by acting in the ways that she has set out, she was 'able to maintain my own dignity', an upshot that is designed to undermine any ascription of identity associated with potentially 
sexualised activity.

\section{Collaboratively Avoiding Unwelcome Identity}

We saw above how group members could use detail to dodge the ascription of an unwelcome identity. Group contexts such as this one, of course, do not only allow for participants to seek to seek to negotiate their own accounts of identity but also offer opportunities for others who are co-present in the group setting to build on or contribute to these accounts. In the next extract we see one participant, Pat, provide a description of her own experiences of breastfeeding in public with the contribution and support of Jo who is co-present. This extract arises at a point elsewhere in the interaction where the group have been discussing the ways in which a mother's relative inexperience may compound difficulties experienced when breastfeeding in public.

$\begin{array}{ccl}\text { Extract 3 } & \\ 1 & \text { Pat } & \text { there have been situations where like (.) when I was on the } \\ 2 & & \text { train coming back and I was (.) sitting right (.) so in a sort of (.) } \\ 3 & & \text { it was a disabled space with other people sitting in it and then } \\ 4 & & \text { (.) I was right on the edge and then there was like a guy } \\ 5 & & \text { standing next to me (.) like people standing right next to me } \\ 6 & & \text { that felt quite it was a bit too [ } \\ 7 & \text { Jo } & \text { [intimate } \\ 8 & \text { Pat } & \text { yeah but (.) generally I don't have a problem }\end{array}$

In the extract above Pat, like Val in Extract 2, describes an occasion on which she used a baby apron to cover herself while breastfeeding in public. And, also similarly to Extract 2, this is set out in a context where her actions might have been observable by others co-present at the time. Again, therefore, this description of her activities potentially makes available an unwelcome identification as someone who will engage in inappropriate actions in a public place.

Pat however, like Val earlier, provides a detailed description of the setting that is designed to attend to such possibilities. She provides particularizing description in terms of 'it was a disabled space' (line 3). In characterizing her experience in that space, she provides detail on what she and the other people in the space were doing: 'other people sitting in it' (line 3), 'I was right on the edge' (line 4), 'there was a guy standing next to me' (lines 4-5), 'people standing right next to me' (line 5). These descriptions both describe the space in terms of how she and the other passengers were spatially oriented to one another and also signify the status of those other passengers as strangers in that these individuals are referred to in non-specific ways such as 'other people' (line 3 ) and 'a guy' (line 4).

The use of these vague generalised descriptions of those who were co-present serves to deflect the possibility that Pat was attending to them in the context of the train journey: they were simply other passengers that were of relatively little note to her except in terms of their physical proximity at that time. She begins to describe the difficulty that she experienced, projected at line 6 by 'it was a bit too'. Before she can complete this statement, however, Jo at line 7 offers a candidate term: 'intimate'. This turn both provides collaboration in the account that Pat is producing and does so by completing a contrast between the vague and disinterested descriptions that Pat has given of the other passengers and the inappropriateness of their proximity to her. This allows Pat in her next turn at line 8 to signal her agreement with Jo's candidate completion of the projected contrast and to offer the upshot that 'generally I don't have a problem' (line 8). Pat's action of breastfeeding in the context of this train journey thus is presented as one made uncomfortable by the physical surroundings and people co-present at 
the time, and not one that is to be treated as bound up with ascription of the unwelcome identity of someone who will expose parts of her body in inappropriate circumstances.

\section{Collaborative Use of Detail}

We saw above how those co-present in the group could draw upon the detail provided by others to attend collaboratively to potential issues of identity. In this final pair of extracts, we will see how group members can go beyond collaborative resistance to identity based on the detailed descriptions of others to the actual provision of the necessary detail where it has not previously been made available in the preceding turn. The exchange below occurs at a later point in the group's discussion of the difficulties in using baby aprons.

\section{Extract 4 \\ 1 Deb \\ 2 \\ 3 \\ 4 All \\ 5 Deb \\ 6 \\ 7}

I remember (.) like before the café in the country park where I would walk with Rachel and (.) it was such a windy day and I sat on the bench with that on ((laughter)) and it was blowing up over my face and I didn't see anything (.) coat's blowing around (.) this is not what it's supposed to be like trying to feed her

In contrast to the descriptions seen in Extracts 2 and 3, in which group members described using baby aprons to avoid exposing parts of their bodies, Deb in this extract describes an occasion of breastfeeding in public that makes available the opposite inference. Her reference at lines 1 to 3 of walking with her baby outside on 'such a windy day' projects a description to follow of difficulties resulting from doing so. Indeed, the collusive laughter of other group members at line 4 signals their expectation that such difficulties are to be recounted.

As Deb continues at line 5, she goes on to describe the sorts of difficulties that have been previously signalled. In the course of this description, Deb refers to 'it' (the baby apron) 'blowing up over my face' (line 5), thereby totally impeding her vision, and of her coat 'blowing around' (line 6) also. The inference from this description is that the baby apron, 'blowing around', did not appropriately cover her while she was breastfeeding her baby on this occasion. And, this outcome is encapsulated in her upshot at lines 6 to 7 'this is not what it's supposed to be like trying to feed her'. Thus, following her description of these actions, albeit in circumstances that gave rise to particular difficulties, she faces the risk of being identified in a manner consistent with these activities.

Unlike Val in Extract 2 and Pat in Extract 3, Deb in providing the detail that she has included has raised the possibility that she might indeed be identified as someone who exposes part of her body in public. This detail, however, does provide scope for another group member to contribute to Deb dodging such an identity as we see below. Extract 5 continues on immediately from the exchange in Extract 4.

\section{Extract 5}

8 Jan you need to take into account Scotland and the weather (.) but

9 you do want somewhere where there's a changing facility and

10 you can ((indistinguishable))

11 Jo so do you think there's enough breast friendly places in

$12 \quad$ public?

Although Deb in Extract 4 did not make any more general claim about her actions of public breastfeeding, unlike Pat in Extract 3, her description nonetheless served to project a 
candidate resolution of her difficulties: public breastfeeding should be conducted in other sorts of circumstances. And at line 8, Jan picks up on this projected resolution in stating that that 'you need to take into account Scotland and the weather'. Likewise, Jan's claim 'you do want somewhere where there's a changing facility' (line 9) reflects what Deb has already said about the time and place she chose to engage in public breastfeeding. The following turn of the facilitator at line 11, which introduces a new topic for general discussion, treats this suggestion as a sufficient formulation of how Deb's difficulties might be addressed. These collaborative turns by others co-present in the discussion thus serve to restrict the actions that Deb described to very specific circumstances, and attend to the possibility that she might be identified in a manner associated with exposure of part of her body on that one occasion.

\section{Discussion}

In reporting this study and its outcomes, we have described how the study was designed and conducted, and have demonstrated how the analysis was produced. Inclusion of the data extracts provided here allows readers to judge for themselves the plausibility and coherence of the findings that are reported. More than this, the findings display fruitfulness in offering insights into how participants in such group settings can develop support for each other and collaboratively deal with problematic issues of identity. In these ways, then, the study meets the criteria specified by McMullen (2021) as relevant to evaluation of a study such as the present one.

The aim of the present study was to examine how mothers who breastfeed in public ward off problematic identifications that might be associated with this activity. The present findings demonstrate the advantages of adopting a discursive approach to study how breastfeeding mothers attend to these issues of identity. Instead of treating a description of experiences of breastfeeding in public as a straightforward depiction of what occurred at a particular time, it is clear that the participants are constructing their accounts of experience in ways that are designed to accomplish specific outcomes in this local setting. And the outcomes towards which these constructions are directed are those of identity. An identity of being a mother who breastfeeds her infant in public is not simply a neutral description of a person who engages in a particular activity. As noted above, this activity is one that is often described as being problematic (Cripe, 2017), and regarded as such by mothers themselves (Boyer, 2018; Carathers, 2017). It is unsurprising therefore that the participants in this study orient to it as problematic. The ways in which they discursively manage their accounts of their experiences are designed not just to avoid criticism but also to negotiate their own identities that emerge from the interaction. Identity is a live issue here for the participants, and we see how they attend to the potential problems of identity that might arise were they not to construct their experiences as they do. What is of particular note, here, is how the context of a discussion with others who have similar experiences and concerns allows the participants collaboratively to accomplish this. Recent research has shown how in the course of an ongoing discussion speakers can seek to defend others who are not co-present against unwanted ascriptions of identity (McVittie et al., 2020); here, we see how others can seek to address potential problems of identity where the individual to be identified is co-present in the discussion.

More specifically, these findings show how the inclusion of detail in a description of actions and events can be used not to bolster a specific claim to identity based upon that description but instead to ward off an unwelcome of ascription of identity that might result from a less detailed description. In Extract 1, we see how Jan's general and idiomatic description of public breastfeeding as 'getting their tits out' renders problematic any attempt to undermine such a formulation: the design of the description does not readily make for challenge and subsequent talk is organised around the negative identity associated with this description. In the subsequent extracts, however, it is the inclusion of detail that allows for the undermining of the 
potentially problematic description that is in play and the avoidance of the identity that might follow from such a description of events. Thus, in Extract 2, we see how Val can deploy detail of her actions, her baby's actions, and others co-present on a specific occasion to deflect any suggestion that the action of having her 'boob out' falls to be understood in a socially inappropriate way. And, moreover, as seen In Extracts 3, 4, and 5, other group members can pick up on the detail provided in the initial description or supplement such detail in order collaboratively to attend to the problematic actions and identity that are in play.

Thus, whereas in Potter's (1996) example of the relationship dispute between Connie and Jimmy detail was included in an attempt to warrant Jimmy's description of Connie as someone who behaved inappropriately, here such detail functions in the opposite manner, that is to allow the speaker who provides that detail to avoid an ascription of identity consistent with inappropriate behaviour. In this respect, it is useful to note more particularly how such detail operates in descriptions of this sort. As Potter (1996) points out, by providing detail in any such description speakers are making that detail available to the recipients of the description for inspection: 'one feature of detail is that it can be inspected for contradictions and confusions or provide material that can be reworked into a different kind of narrative entirely' (p. 166). And, although that inspection might be troublesome in relation to ascriptions of specific forms of identity, inspection of detail that leads to the undermining and reworking of an unwelcome identity can be a desired outcome. While therefore the general and idiomatic description seen in Extract 1 does not readily allow for such reworking, it is the detailed descriptions in the subsequent extracts that offer scope for reworking the descriptions of actions and events and the identities that ensue from these.

One point that we can note from the findings presented here, and indeed from the entire discussions of the focus group, is that at no point in their discussions did the participants offer any description of public breastfeeding that could be regarded as evaluatively positive. Although breastfeeding has been continuously promoted by The Royal College of Midwives (1918) as the most nurturing and preferred method of feeding young infants, and writers have pointed to the identity of 'good mother' (Shaw et al., 2003) that potentially at least is associated with this activity, none of the present participants made any such claims in relation to the activity or this potential identity. Instead, throughout their discussions, the participants oriented to rather more problematic descriptions of their actions, encapsulated in Jan's description in Extract 1 of 'getting their tits out'. These orientations, moreover, came from the participants' own descriptions as produced in the discussions: the questions and topic initiators produced by the group facilitator were designed to be evaluatively neutral, for example 'could you say a bit about your experiences ...'

The question arises, then, of why the participants, in producing their descriptions here, orient to avoiding problematic versions of public breastfeeding and negative ascriptions of identity rather than seeking to make more positive claims. One possible reason for this orientation might lie in the composition of this focus group, in which all participants were members of a support group for breastfeeding mothers. Given that their talk was designed to be received by those who engaged in public breastfeeding, it is unsurprising that in discussing such matters the participants treated the activity of breastfeeding in public as one to be valued and supported: without such shared understanding of their actions, it would make little sense for those involved to be seeking the support of others in continuing with them.

An alternative, but not mutually exclusive, possibility is that the descriptions that the participants produced here were indeed designed to highlight the problems involved in these actions. Antaki and Wetherell (1999) identified a form of argumentation that they term 'show concessions', in which a proposition is advanced, a speaker makes a concession to some counter-proposition, and that concession is then used to restate more strongly the original proposition. In the present case, taking the arguments in favour of public breastfeeding to be shared understandings for members of this particular group, the details provided of occasions 
on which this activity had been found to be problematic offer some concession to the possibility that such behaviour does fall to be treated as inappropriate. The subsequent undermining of the participants' detailed concessions thus allows for reinstatement of public breastfeeding as something that is to be positively evaluated. And, by highlighting their problems, through episodes of 'troubles-telling' (Jefferson, 2015), the participants are able to identify themselves as individuals who are able not just to cope with the troubles but who can overcome these troubles. These co-constructions thus demonstrate group members' commitment to public breastfeeding as an activity that is to be pursued regardless of particular problems that might arise along the way.

Here, then, in these ways the detail provided that the participants provide, individually and collaboratively, allows them both to rework the actions at hand to avoid ascriptions of problematic identity and to demonstrate that they are capable not just of overcoming such troubles but also of attending to the social concerns that often are associated with mothers who breastfeed in public.

\section{References}

Acker, M. (2009). Breast is best...but not everywhere: Ambivalent sexism and attitudes toward private and public breastfeeding. Sex Roles, 61, 476-490. https://doi.org/10.1007/s11199-009-9655-z

Antaki, C., \& Wetherell, M. (1999). Show concessions. Discourse Studies, 1, 7-27. https://doi.org/10.1177/1461445699001001002

Boyer, K. (2018). The emotional resonances of breastfeeding in public: The role of strangers in breastfeeding practice. Emotion, Space \& Society, 26, 33-4. http://dx.doi.org/10.1016/j.emospa.2016.09.002

British Psychological Society. (2014). Code of Human Research Ethics. The British Psychological Society.

Burns, E., Schmied, V., Fenwick, J., \& Sheehan, A. (2012). Liquid gold from the milkbar: Constructions of breastmilk and breastfeeding women in the language and practices of midwives. Social Science and Medicine, 75, 1737-1745. https://doi.org/10.1016/j.socscimed.2012.07.035

Carathers, J. (2017). The breastfeeding problematic: Negotiating maternal sexuality in heterosexual partnerships. Women's Studies International Forum, 65, 71-77. https://doi.org/10.1016/j.wsif.2017.10.002

Cripe, E. T. (2017). "You can't bring your cat to work": Challenges mothers face combining breastfeeding and working. Qualitative Research Reports in Communication, 18(1), 3644. https://doi.org/10.1080/17459435.2017.1294615

Drew, P., \& Holt, E. (1989). Complainable matters: The use of idiomatic expressions in making complaints. Social Problems, 501-520. http://dx.doi.org/10.1525/sp.1988.35.4.03a00060

Edwards, D. (2003). Analyzing racial discourse: The discursive psychology of mind-world relationships. In H. van den Berg, M. Wetherell, \& H. Houtkoop-Steenstra (Eds.), Analyzing race talk: Multidisciplinary approaches to the interview (pp. 31-48). Cambridge University Press.

Edwards, D., \& Potter, J. (1992). Discursive psychology. Sage.

Fenwick, J., Burns, E., Sheehan, A., \& Schmied, V. (2013). 'We only talk about breast feeding': A discourse analysis of infant feeding messages in antenatal group-based education. Midwifery, 29, 425-433. https://doi.org/doi:10.1016/j.midw.2012.02.006

Gammie, E., Hamilton, S., \& Gilchrist, V. (2017). Focus group discussions. In Z. Hoque, I. D. Parker, M. A. Covaleski, \& K. Haynes (Eds.), The Routledge Companion to Qualitative Accounting Research Methods (pp. 372-386). Routledge. 
Garfinkel, H. (1967). Studies in ethnomethodology. Prentice Hall.

Hennink, M. M. (2014). Focus group discussions: Understanding qualitative research. Oxford University Press.

Jefferson, G. (2004). Glossary of transcript symbols with an introduction. In G. H. Lerner (Ed.), Conversation analysis: Studies from the first generation (pp. 13-31). John Benjamins.

Jefferson, G. (2015). Talking about troubles in conversation. Oxford University Press.

Johnston-Robledo, I., Wares, S., Fricker, J., \& Pasek, L. (2007). Indecent exposure: Selfobjectification and young women's attitudes toward breastfeeding. Sex Roles, 56, 429437. https://doi.org/10.1007/s11199-007-9194-4

Locke, A. (2009). 'Natural versus taught': Competing discourses in antenatal breastfeeding workshops. Journal of Health Psychology, 14(3) 435-44. https://doi.org/10.1177/1359105309102200

Mahon-Daly, P., \& Andrews, G. (2002). Liminality and breastfeeding: Women negotiating space and two bodies. Health \& Place, 8, 61-76. https://doi.org/10.1016/S13538292(01)00026-0

McFadden, A., \& Toole, G. (2006). Exploring women's views of breastfeeding: A focus group study within an area with high levels of socio-economic deprivation. Maternal \& Child Nutrition, 2, 156-168. https://doi.org/10.1111/j.1740-8709.2006.00054.x

McKinlay, A., \& McVittie, C. (2008). Social psychology and discourse. Wiley-Blackwell.

McKinlay, A., \& McVittie, C. (2011). Identities in context: Individuals and discourse in action. Wiley-Blackwell.

McMullen, L. M. (2021). Essentials of discursive psychology. American Psychological Association.

McVittie, C., McKinlay, A., \& Munro, R. (2020) 'A Golly was simply a toy. End of': Inoculation, attention deflection, and attempted puzzle-resolution in contesting racism in online discussions. European Journal of Social Psychology, 50(3), 673-684. https://doi.org/10.1002/ejsp.2640

Pomerantz, A. M. (1986). Extreme case formulations: A new way of legitimating claims. Human Studies, 9, 219-230. https://doi.org/10.1007/BF00148128

Potter, J. (1996). Representing reality: Discourse, rhetoric, and social construction. Sage.

Puchta, C., \& Potter, J. (2004). Focus group practice. Sage.

Sacks, H. (1992). Lectures on conversation. Blackwell.

Scott, J., \& Mostyn, T. (2003). Women's experiences of breastfeeding in a bottle-feeding culture. Journal of Human Lactation, 19, 270-277. https://doi.org/10.1177/0890334403255225

Shaw, R. L., Wallace, L. M., \& Bansal, M. (2003). Is breast best? Perceptions of infant feeding. Community Practitioner, 76, 299-303.

Stearns, C. (1999). Breastfeeding and the good maternal body. Gender \& Society, 13, 308-325. https://doi.org/10.1177/089124399013003003

Stokoe, E. (2010). 'I'm not gonna hit a lady': Conversation analysis, membership categorization and men's denials of violence towards women. Discourse \& Society, 21, 59-82. https://doi.org/10.1177/0957926509345072

Stokoe, E., \& Edwards, D. (2007). 'Black this, Black that': Racial insults and reported speech in neighbour complaints and policy interrogations. Discourse \& Society, 18, 337-372. https://doi.org/10.1177/0957926507075477

The Royal College of Midwives. (2018). Position statement: Infant feeding. The Royal College of Midwives.

Tracy, K., \& Robles, J. S. (2013). Everyday talk: Building and reflecting identities. Guilford Press.

Widdicombe, S. (1998). Identity as an analysts' and a participants' resource. In C. Antaki \& S. Widdicombe (Eds.), Identities in talk (pp. 191-206). Sage. 
Wiggins, S. (2017). Discursive psychology: Theory, method, and applications. Sage.

Wilkinson, S. (1999). Focus groups: A feminist method. Psychology of Women Quarterly, 23, 221-244. https://doi.org/10.1111/j.1471-6402.1999.tb00355.x

\section{Notes on Contributors}

Paola Taormina completed her undergraduate studies in psychology and sociology at Queen Margaret University, Edinburgh, UK. Following graduation, she worked with the Cyrenians organization and designed, implemented and led a new programme on prisoner engagement within the Scottish Prisons sector.

Chris McVittie publishes widely on topics of discourse, identities, social groups, and social inclusion/exclusion. He is co-author (with Andy McKinlay) of Social psychology and discourse (Wiley-Blackwell, 2008), and Identities in context: Individuals and discourse in action (Wiley-Blackwell, 2011), and co-author (with Steve Kirkwood, Simon Goodman, and Andy McKinlay) of The language of asylum: Refugees and discourse (Palgrave Macmillan, 2015).

Andy McKinlay is Professor Emeritus in the Department of Psychology within the School of Philosophy, Psychology and Language Sciences at The University of Edinburgh. His research interests lie in the study of identities, social groups and intergroup relations and how they are negotiated in discourse and he has published widely on these and associated topics.

Manuscript received October 5, 2020 Final revision received February 18, 2021 Accepted February 22, 2021 